\title{
Monte-Carlo Simulation of Helicopter Noise
}

\author{
József Bera ${ }^{1}$ and László Pokorádi ${ }^{2}$ \\ ${ }^{1}$ Óbuda University, Doctoral School of Safety and Security Sciences, \\ Népszínház u. 8, H-1081 Budapest, Hungary, e-mail: bera.jozsef@ prosysmod.hu \\ 2 Óbuda University, Donát Bánki Faculty of Mechanical and Safety Engineering, \\ Népszínház u. 8, H-1081 Budapest, Hungary, e-mail: pokoradi.laszlo@bgk.uni- \\ obuda.hu
}

\begin{abstract}
Currently, applied flying noise investigation methods are done from energetic points of view, independent of other noise sources. These methods do not adequately accept the ground state of the environment and its changes. This paper proposes a new MonteCarlo Simulation-based investigation method, to analyze changes of environment states when the number and characteristics of flying operations and noise levels fluctuate stochastically.
\end{abstract}

Keywords: environment protection; noise; helicopter; Monte-Carlo Simulation

\section{Introduction}

These days the number of flights over living spaces is increasing. Flight noise investigation is currently done from only energetic points of view, independent of other noise sources. Therefore, the ground state of the environment and its changes do not get enough attention, so flight noise, is analyzed as if it would create more noise sources.

The approaches mentioned above lack subjective observation. This is a big problem in the case of the noise, which is called energy pollution or disturbed transfer of energy [4] that usually generates an immediate reaction from the observers and the environment.

There is an important question. Which method is adaptable to depict correct changes of environment state when the numbers and characters of flying operations and related noise levels are different in time? This study proposes a new simulation method based on a Monte-Carlo Simulation to answer this question. 
The Monte-Carlo Simulation is one of the most well-known parametric uncertainty investigation methods. There are several books and studies that mention the theory of the Monte-Carlo Simulation and its applications.

Newman and Barkema describe the Monte-Carlo Simulation and its application opportunities to investigate several scientific problems [10]. Pokorádi has summarized the theoretical background of the mathematical modeling of technical systems and processes [12].

In the study of Madić and Radovanović, an attempt was made to investigate the Monte-Carlo Method applicability for solving single-objective optimization problems [8]. Based on the results, they proposed a wider application of the Monte-Carlo Method for solving machining optimization problems because of its simplicity, efficiency and wide-ranging capabilities.

Morariu and Zaharia presented a calculation methodology of the testing duration of the products' reliability. Their proposed methodology and the accuracy of the results were verified by using the Monte-Carlo data simulation method [8].

Sobor et al. analyzed the evolution of jet passenger aircraft noise and uncertainty of its determination [13]. They used probability calculation analysis.

The Authors have investigated noise protection questions of helicopters and aerial and other types of transportation [1] [2] [3] [4] [5]. These publications showed measured data which are used in the Monte-Carlo Simulation (see Table 1).

The outline of the study is the following: Section 2 shows the model of flying noise emission. Section 3 depicts the Monte-Carlo briefly. Section 4 demonstrates an assessment method of helicopter noise emission used Monte-Carlo Simulation. Section 5 summarizes the study, outlines the prospective scientific work of the Authors.

\section{Helicopter Noise Effect Model}

The noise pressure $L_{\text {Aeq }}$, is mostly related to the changes of state of environment parameters. This noise pressure level which characterizes the observed influence of noise, is an equivalent parameter constituted by maximum and minimum sound pressures [4]. In case of aerobatic flies of helicopters uncertainties of equivalent noise pressures of maneuvers should be characterized by their distribution (see Figure 3).

The equivalent noise pressure is in accord with changes of pressure in the environment. But disturbance depends on time of noise effect too. Therefore, the duration of noise effect should be taken into account during the modeling of noise. The average noise load $L_{A X j}$ of (the $j^{t h}$ ) maneuver $[\mathrm{dB}]$ can be determined by the following equation: 


$$
L_{A X, j}=L_{A e q, j}+10 \cdot \lg \frac{\tau_{j}}{\tau_{r e f}}[\mathrm{~dB}]
$$

where:

$\begin{array}{lll}\tau_{j .} & - & \text { time of }\left(\text { the } j^{\text {th }}\right) \text { maneuver }[\mathrm{s}] \\ L_{\text {Aeqj }} & - & \text { equivalent noise pressure of }\left(\text { the } j^{\text {th }} \text { ) maneuver }[\mathrm{dB}]\right. \\ \tau_{\text {ref. }} & - & \text { reference time: } 1 \mathrm{~s}\end{array}$

The authoritative acoustical pressure level occurred from aerobatics $L_{A M, r e}$ can be determined by the following equation [4]:

$$
L_{A M, r e}=10 \cdot \lg \frac{\tau_{r e f}}{T_{M}} \sum_{j=1}^{M} 10^{0,1 \cdot L_{A X j}^{\prime}}[\mathrm{dB}]
$$

where:

$\begin{array}{lll}T_{M} & - & \text { time of estimation [s] } \\ M & - & \text { number of flying maneuvers }\end{array}$

The used time of estimation is $1800 \mathrm{~s}$ ( $30 \mathrm{~min}$ ), because the average time of one aerobatic fly operation is 30 minutes.

The applications of equations (1) and (2) are in Hungary and in the European Union. These equations will be used during our investigation to estimate noise load of a helicopter aerobatics. In other words, equations (1) and (2) will be the model of the investigated helicopter flying operations. These equation determined by European and Hungarian regulations, therefore, the applied model has to be validated.

We can see that these equations compose a deterministic mathematical model of helicopter aerobatic noise. But the time of the maneuver is a variable parameter, that can be characterized by its distribution function (see Figure 4). The number of maneuvers is a fluent parameter too (see Figure 5). Therefore, in order to investigate this environmental protection problem (basically a deterministic model with stochastic input parameters) the Monte-Carlo Simulation should be used.

\section{The Monte-Carlo Simulation}

Monte-Carlo is one of the well-known classical simulation techniques. The name Monte-Carlo was applied to this class of mathematical methods by scientists working on the development of nuclear weapons during the Manhattan Project in Los Alamos [7]. All Monte-Carlo Simulations have the following common features: 
1) A known $f(x)$ probability density function over the set of system inputs.

2) Random sampling of inputs based on the distribution specified in feature 1) and simulation of the system under the selected inputs.

3) Numerical aggregation of experimental data collected from multiple simulations conducted according to feature 2) [6].

Numerical experiments of Monte-Carlo Simulation lead us to run the simulation on many sampled inputs before we can infer the values of the most interesting system performance measures.

At its heart it is a computational procedure in which a performance measure is estimated using samples drawn randomly from a population with appropriate statistical properties. The selection of samples, in turn, requires an appropriate random number generator. During our investigation the Hit and Miss (Acceptance-Rejection) Method will be used. This method, which is related to John von Neumann, contains random samplings from an appropriate distribution and subjecting it to a test to determine whether or not it will be acceptable for use.



Figure 1

Illustration of Acceptance-Rejection Method

First, the $f(x)$ probability density function and interval of the generated parameter should be determined (see Fig. 1). They can be defined by statistical Monte-Carlo Simulation of the pipeline system to investigate effects of the thermal water temperature of the real measured data or they can be assumed by preliminary experiences. Then two independent random values $x$ from $\left[x_{\min } ; x_{\max }\right]$ and $\mathrm{y}_{\mathrm{x}}$ from $(0 ; 1)$ intervals are generated and tested to see whether there are inequalities or not

$$
y_{x}<f(x)
$$

holds:

\& If the inequality holds, then accept $x$ as a variable generated from $f(x)$ (see B point in Figure 1).

* If the inequality is violated, reject the pair $x, y_{x}$ (see A point in Figure 1) and try again. 
The Acceptance-Rejection Method can be executed simply and can generate random numbers to any kind of distribution [11].

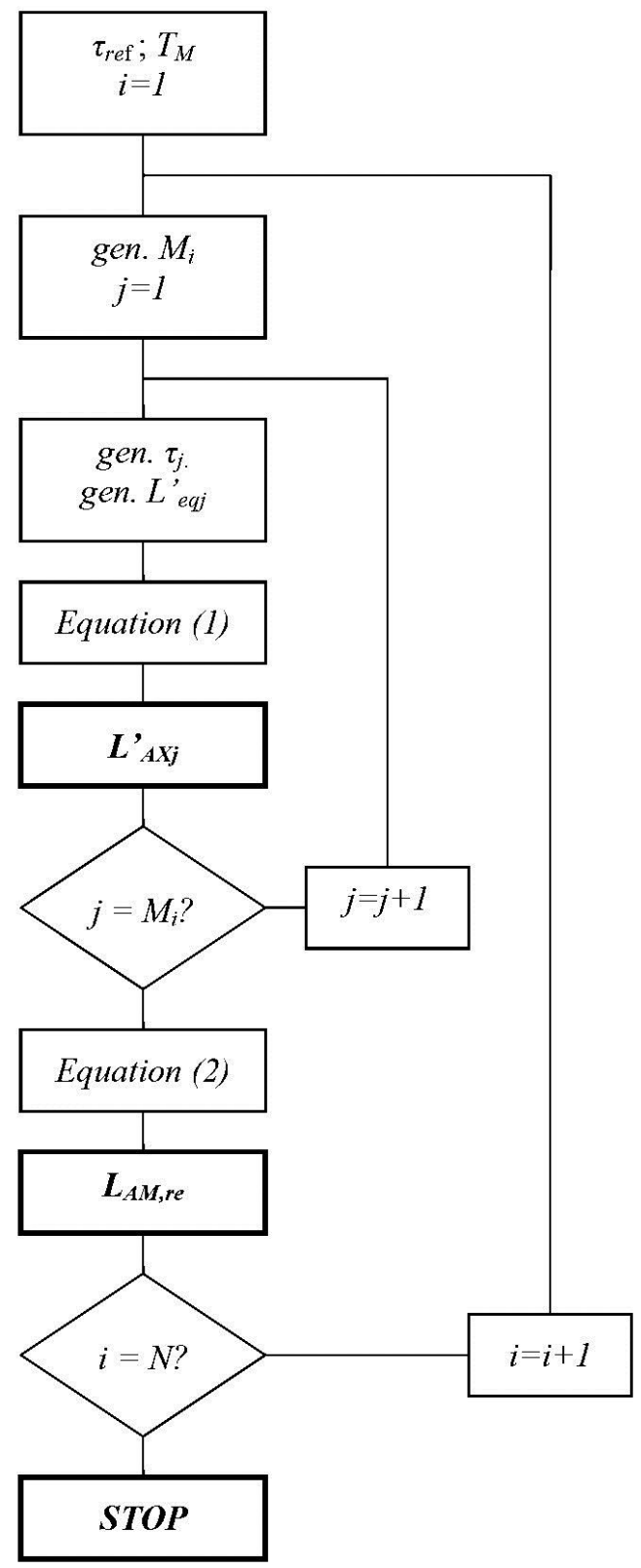

Figure 2

Block Diagram of the Monte-Carlo Simulation 


\section{Helicopter Noise Simulation}

During the investigation of the equations (1) and (2) form the deterministic model which has been excited by different $M$ numbers of maneuvers, $\tau$ time of maneuver and $L_{\text {eq }}$ equivalent noise pressure.

\subsection{The Simulation}

The block diagram of the simulation can be seen in Figure 2. The number of model generations $N$ was 1500 . The basic statistical data is shown by Table 1 . Investigation of Sobor et al. showed that the change of equivalent noise depends on the differences of the independent parameters of noise events but it is independent of the type of their distributions [13]. During the simulation, the Acceptance-Rejection Method shown in Chapter 3 was used. The density functions were chosen by our measuring [1] and general engineering experiences (see Table 1 right column). The histograms of applied excitation values are shown by Figures 3-5.

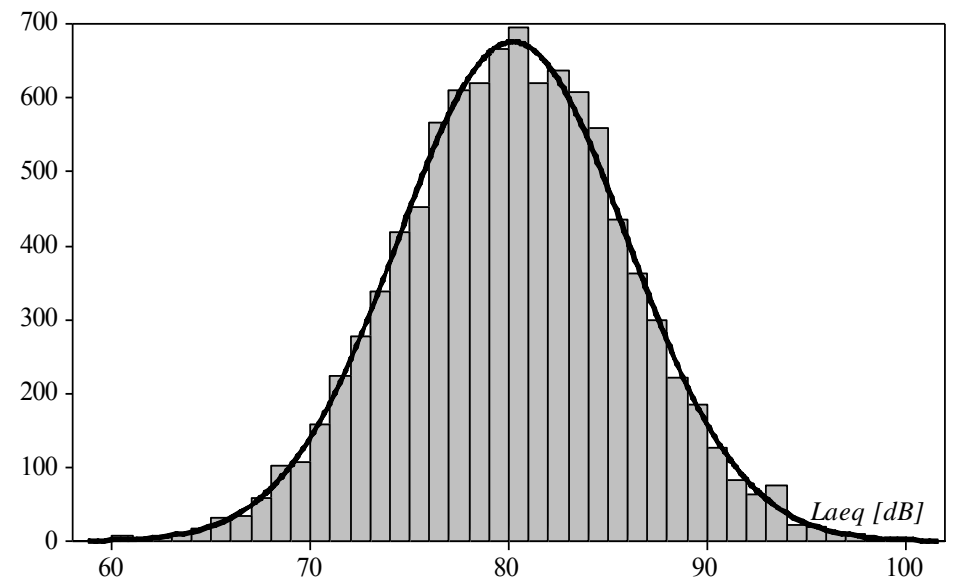

Figure 3

Histogram of Equivalent Noise Pressures $\left(L_{\text {Aeq }}\right)$ 




Figure 4

Histogram of Times of Maneuvers $(t)$

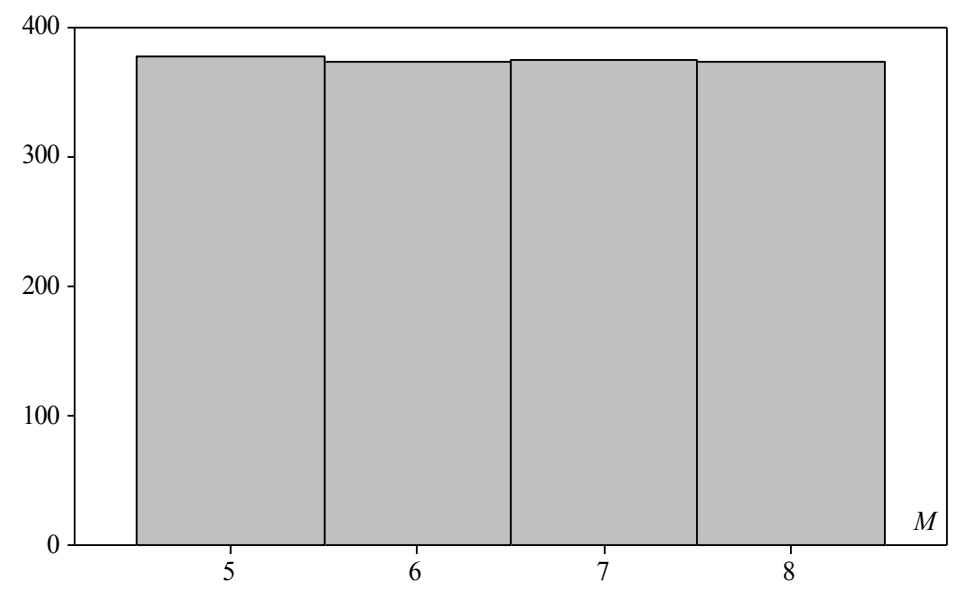

Figure 5

Histogram of Numbers of Maneuvers $(M)$ 
Table 1

Statistical Data of Excitation Values

\begin{tabular}{|c|c|c|c|c|c|}
\hline & Min. & Mean & Max. & Dev. & Density Function \\
\hline$L_{e q-m}^{\prime}[\mathrm{dB}]$ & 58.3 & 80.2 & 102.4 & & \multirow{2}{*}{ Normal } \\
\hline$L_{e q-e x}^{\prime}[\mathrm{dB}]$ & 58.6 & 80.2 & 101.1 & 5.75 & \\
\hline$M_{-m}[-]$ & 5 & 6.5 & 8 & & \multirow{2}{*}{ Uniform } \\
\hline$M_{-e x}[-]$ & 5 & 6.497 & 8 & 1.12 & \\
\hline$\tau_{-m}[\mathrm{~s}]$ & 1.5 & 17.5 & 33.5 & & \multirow{2}{*}{ Normal } \\
\hline$\tau_{-e x}[\mathrm{~s}]$ & 1.52 & 17.44 & 33.35 & 4.14 & \\
\hline
\end{tabular}

\subsection{Results and Discussion}

From the results of the simulation, the following conclusions can be deduced:

1. The Monte-Carlo Simulation can be used to analyze noise effects of helicopter aerobatics.

2. The noise pressure $L_{A e q}$ and acoustical pressure level $L_{A M, r e}$, as unique limits, are inappropriate to investigate subjective noise observations and to make decisions that satisfy the condition of compromises. Additional indicators should be introduced for correct assessment.

3. Due to uncertainties of environmental factors affecting the noise transmission measured values can have significant differences.



Figure 6

Density Function of Average Noise Loads $\left(L_{A X}\right)$ 



Figure 7

Density Functions of Authoritative Acoustical Pressure Levels in Cases of Different Numbers of Maneuvers $\left(L_{A M, r e}\right)$ 
4. The duration of the maneuvers resultant in the $L_{A X}$ values used in valuation interval increased to $+10 \mathrm{~dB}$ (see Figures 3 and 6). Namely, we consider 10 $\mathrm{dB}$ higher values of the assessment. It suggests focusing on the level of disturbance.

5. Figure 8 shows consequence of the preferably determined time of estimation. Based on these results, we draw the conclusion, that the distribution function is shifted towards lower noise levels and a narrower range of 60 to $80 \mathrm{~dB}$ added values.

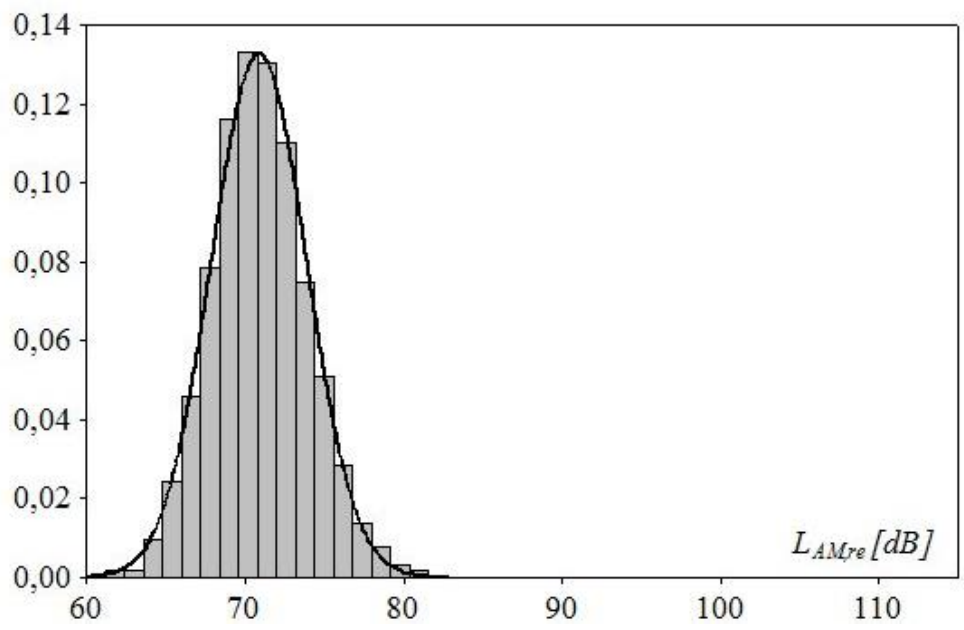

Figure 8

Density Function of Authoritative Acoustical Pressure Level $\left(L_{A M, r e}\right)$

6. The number of maneuvers determines the total duration of noisy periods and its ratio to the quiet period. This is significant because the exposure time (durations of maneuvers) play a central role in reducing noise levels. So, the importance of number and times of maneuvers should be highlighted in the evaluation process.

7. The applied model should be set up to following points of view:

* The measured noise pressure $L_{\text {Aeq }}$ shows a short period in the change of environment status based on the maximum and minimum sound pressure level values.

\& The time of estimation $T_{M}$ equal to the duration of aerobatic flying operation allows for a more realistic analysis and more effective decisions.

8. For realistic results, the measured pressure levels and their distributions have to be investigated, instead of, the average noise parameters. 


\section{Conclusions and Future Work}

This paper proposed a Monte-Carlo Simulation-based method to investigate the noise load of helicopter aerobatics.

The research work and its results demonstrate that parameters of environmental systems are uncertain. Applying only unique key numbers to depict environmental problems and their comparison with threshold values are not allowed. The density functions of environmental system parameters should be used to investigate different loads of environment.

During prospective scientific research, related to this field of environmental protection and applied mathematics, the Authors would like to develop other methodologies to model and investigate the environmental effects of aviation and other means of transport.

\section{References}

[1] Bera J. - Pokorádi L.: Actual Question of Measuring of the Aircraft Noise, The Challenge of Next Millennium on Hungarian Aeronautical Sciences (12 $2^{\text {th }}$ Hungarian Days of Aeronautical Sciences), pp. 114-123

[2] Bera J. - Pokorádi L.: Industrial Helicopter Application and its Noise Protection Problems, Proceedings of the $12^{\text {th }}$ Mini Conference on Vehicle System Dynamics, Identification and Anomalies, Budapest, November 810, 2010, ISBN: 978963313058 2, pp. 343-350

[3] Bera J. - Pokorádi L.: Noise Protection Investigation of Heliports, Proceedings of the $11^{\text {th }}$ Mini Conference on Vehicle System Dynamics, Identification and Anomalies, Budapest, 10-12 November, 2008, (ISBN $9789633130117)$, pp. 577-581

[4] Bera J. - Pokorádi L.: Theory and Practice of Helicopter Noise, Campus Kiadó, Debrecen, 2010, 192 p. (in Hungarian)

[5] Bera J.: Noiseprotectional Design of Heliports, Repüléstudományi Közlemények Különszám, 2007. április, Szolnok (CD-version) (in Hungarian)

http://www.szrfk.hu/rtk/kulonszamok/2007_cikkek/bera_jozsef.pdf.

[6] Guizani, M., Rayes, A., Khan, B., Al-Fuqaha, A., Network Modeling and Simulation, A Practical Respective, John Wiley \& Sons, Chichester, 2010, p. 281

[7] Kalos M. H. and P. A. Whitlock Monte-Carlo Methods. Second Edition 2008 WILEY-VCH Verlag GmbH \& Co. KGaA, Weinheim

[8] Miloš Madić; Miroslav Radovanović, Possibilities of Using The MonteCarlo Method for Solving Machining Optimization Problems, Facta Universitatis, Mechanical Engineering Vol. 12, No. 1, 2014, pp. 27-36 
[9] Morariu Cristin Olimpiu, Sebastian Marian Zaharia, A New Method for Determining the Reliability Testing Period Using Weibull Distribution, Acta Polytechnica Hungarica, Vol. 10, No. 7, 2013, pp. 171-186

[10] Newman M. E. J., Barkema G. T.: Monte-Carlo Methods in Statistical Physics, Oxford University Press Inc., New York, 1999, p. 475

[11] Pokorádi László, Molnár Boglárka, Monte-Carlo Simulation of the Pipeline System to Investigate water Temperature's Effects, Polytechnical University of Bucharest. Scientific Bulletin. Series D: Mechanical Engineering 73:(4) pp. 223-236 (2011)

[12] Pokorádi, L.: Systems and Processes Modeling, Campus Kiadó, Debrecen, 2008, p. 242 (in Hungarian)

[13] Sobor Á. et. al.: The Evolution of the Equivalent Noise Level of Aircraft Depending on Spreading of the Route, Kép és Hangtechnika XXVIII. pp. 190-192 (in Hungarian) 